\title{
Initiation of parenteral nutrition in critically ill patients
}

\author{
Suganya Sabaretnam ${ }^{1 *}$, LP Chamara Warnapura ${ }^{2}$ \\ Specialty doctor ${ }^{1 *}$ Consultant Anaesthetist and Intensivist ${ }^{2}$, Luton and Dunstable University Hospital, \\ United Kingdom. \\ *Corresponding author: Suganya.Sabaretnam@1dh.nhs.uk
}

\begin{abstract}
Retrospective cross-sectional single centre study was done to determine the current intensive treatment unit (ITU) practice on initiation of parenteral nutrition (PN) and to compare ITU practice with regards to PN against the standard agreed by the East of England critical care network of United Kingdom. All the patients who met the criteria and was admitted to the ITU of Luton and Dunstable University Hospital, United Kingdom from $1^{\text {st }}$ of October to $31^{\text {st }}$ December 2017 were included in the study.
\end{abstract}

Out of the 100 patients in the study, only $10 \%$ were initiated on PN during the ITU stay. All those who received PN were at higher risk of malnutrition as assessed by the malnutrition universal screening tool (MUST) score. The mean days of ITU stay was 3.4 prior to initiating parenteral nutrition. The mean ITU stay of PN group was 8.7 days vs 4.47 in the other group. The ITU and hospital mortality was higher in PN group at $30 \%$ and $50 \%$.

Keywords: Parenteral nutrition; MUST score; critically ill patient

\section{Introduction}

Nutrition is important in critically ill patients. Sickness prevents patients from receiving adequate nutrition due to anorexia, nausea, vomiting, procedural fasting and the ability to absorb from the gut. Malnutrition is known to be associated with increased length of critical care stay, incidence of infection, ventilator dependency, poorer functional status at hospital discharge and death. ${ }^{1}$

The timing of PN has always been a controversy in the critically ill patients. In patients who are adequately nourished prior to intensive care admission, PN initiated within first seven days of intensive care stay has been associated with harm or at best no benefit, in terms of survival and length of stay in intensive care. ${ }^{2}$

Early PN is also associated with unnecessary cost. Luton and Dunstable hospital belongs to the
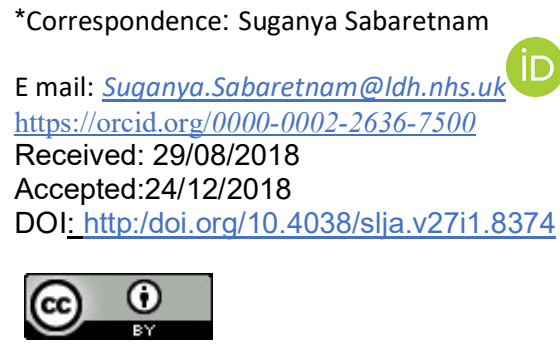

East of England critical care operational delivery network which recommends that PN should not be given to adequately nourished critically ill patients in the first seven days of an intensive care unit stay. ${ }^{3}$

The European Society for clinical Nutrition and Metabolism recommends that all patients who are not expected to be on normal nutrition within 3 days should receive PN within 24 to $48 \mathrm{hrs}$ if enteral nutrition (EN) is contraindicated or if they cannot tolerate it. ${ }^{4}$

In contrast to the European one, the American Society for Parenteral and Enteral Nutrition suggests that in patients at low nutrition risk, exclusive parenteral nutrition should be withheld over the first 7 days following intensive care admission if the patient cannot maintain volitional intake and if early enteral nutrition is not feasible. ${ }^{5}$

EPaNIC trial was a randomised multi-centre trial which compared early initiation of $\mathrm{PN}$ to supplement EN (within 48 hours) to late initiation of parenteral supplementation (after 7 days). It found that initiating of parenteral nutrition later was associated with earlier recovery and less complications. $^{2}$

A study conducted in Turkey among patients with severe pulmonary sepsis showed that the 
requirement of $\mathrm{PN}$ due to intolerance of $\mathrm{EN}$ was associated with a higher mortality rate. ${ }^{6}$

\section{Methodology}

Our main objective was to find out whether parenteral nutrition was given to adequately nourished critically ill patients in the first seven days of intensive care unit stay. In addition, we also aimed to find about the nutritional status of the patients by their MUST score and albumin concentration on admission to the unit.

It was a retrospective cross sectional single centre study. The required data was collected from the patient's electronic records, monitoring charts and electronic investigation reporting system by the lead investigator.

All the non-elective admissions to the intensive treatment unit from $1^{\text {st }}$ October to $31^{\text {st }}$ December 2017 were included in the study with the exception of following - younger than 18 years, short bowel syndrome, advanced wishes against $\mathrm{PN}$ and pregnancy.

We collected data about the patient's BMI score, unexplained weight loss score, acute disease effect score, albumin concentration on admission, PN start day, indication, length of stay in ITU, status at unit discharge and status at hospital discharge.

According to the trust policy, all patients must have their nutritional status assessed on admission utilizing the MUST scoring system.

Table 1: MUST score and the relevant risk of malnutrition predicted from the score

MUST score $=$ BMI score + unexplained weight loss score + acute disease effect score.

\begin{tabular}{|l|l|}
\hline MUST score & $\begin{array}{l}\text { Risk of } \\
\text { malnutrition }\end{array}$ \\
\hline 0 & Low \\
\hline 1 & Medium \\
\hline 2 & High \\
\hline
\end{tabular}

Table 2: Relationship between the BMI and the relevant score

The BMI score was scored as following.

\begin{tabular}{|l|l|}
\hline BMI $\left(\mathbf{k g} / \mathbf{m}^{\mathbf{2}}\right)$ & $\begin{array}{l}\text { BMI } \\
\text { score }\end{array}$ \\
\hline$>20(>30$ Obese $)$ & 0 \\
\hline $18.5-20$ & 1 \\
\hline$<18.5$ & 2 \\
\hline
\end{tabular}

The unexplained weight loss score is an objective scoring system where the patient's previous known weight is assessed against the admission weight.

Table 3: Relationship between unexplained weight loss in past 3-6 months and its relevant score

\begin{tabular}{|l|l|}
\hline $\begin{array}{l}\text { Unexplained weight loss in past 3-6 } \\
\text { months }\end{array}$ & Score \\
\hline$<5 \%$ loss & 0 \\
\hline $5-10 \%$ loss & 1 \\
\hline$>10 \%$ loss & 2 \\
\hline
\end{tabular}

The acute disease effect score is a clinical and subjective scoring system. The scorer being the nurse who is admitting the patient to ITU. The score will be 2 if the patient is acutely ill and there has been or is likely to be no nutritional intake for 5 or more days.

The data was entered and analysed using the SPSS statistical package version 21 by the lead investigator.

\section{Results}

The number of patients admitted to the ITU during this period and who met the criteria was 100. The age of the patients included in the study ranged from 22 to 87 years with the mean age being 59 years. Males predominated in admission to the unit at $62 \%$.

The most common indications for admission were non-surgical reasons. This was commonly due to pneumonia, acute respiratory distress syndrome or acute kidney injury. 
Table 4: Indication for admission and the percent from total admissions

\begin{tabular}{|l|l|}
\hline Indication for admission & Percent \\
\hline $\begin{array}{l}\text { Post-operative- after gastro } \\
\text { intestinal surgery }\end{array}$ & 14 \\
\hline $\begin{array}{l}\text { Post-operative non-gastro intestinal } \\
\text { surgery }\end{array}$ & 15 \\
\hline Non-surgical indication & 71 \\
\hline
\end{tabular}

During the study, we found that the MUST scoring assessment was not completed in all the patients as required by the trust policy. The reason for this poor documentation was not studied. There was variance in documentation of its components as well. BMI was documented in $86 \%$ of the patients in this sample. Most of the patients in this sample were well nourished or over nourished.

Table 5: BMI score of the sample studied

\begin{tabular}{|l|l|}
\hline BMI score & Percent \\
\hline 0 & 80 \\
\hline 1 & 4 \\
\hline 2 & 2 \\
\hline Undocumented & 14 \\
\hline
\end{tabular}

The unexplained weight loss score was documented in $83 \%$ of the patients in this sample group.

Table 6: Unexplained weight loss score of the sample studied

\begin{tabular}{|l|l|}
\hline Unexplained weight loss score & Percent \\
\hline 0 & 79 \\
\hline 1 & 3 \\
\hline 2 & 1 \\
\hline Undocumented & 17 \\
\hline
\end{tabular}

Acute disease effect score was documented in $84 \%$ of the patients. $44 \%$ of the patients in the sample group were noted as acutely ill and there had been or likely to be no nutritional intake for $>5$ days.
Overall MUST score was documented in $84 \%$ of the patients. Most of them were at the high risk of malnutrition.

Table 7: MUST score of the sample studied

\begin{tabular}{|l|l|}
\hline MUST score & Percent \\
\hline 0 & 34 \\
\hline 1 & 6 \\
\hline 2 & 44 \\
\hline Undocumented & 16 \\
\hline
\end{tabular}

Albumin concentration on admission ranged from 11 to $40 \mathrm{~g} / \mathrm{l}$. The mean concentration was $26.85 \mathrm{~g} / 1$ in this sample group. Only $14 \%$ of the patients in this sample group had their albumin concentration equal or above $35 \mathrm{~g} / \mathrm{l}$.

Parenteral nutrition was given to $10 \%$ of the patients in this sample group. The mean days of ITU stay prior to initiating parenteral nutrition was 3.4.

Figure 1: The day of initiation of total parenteral nutrition in the sample studied

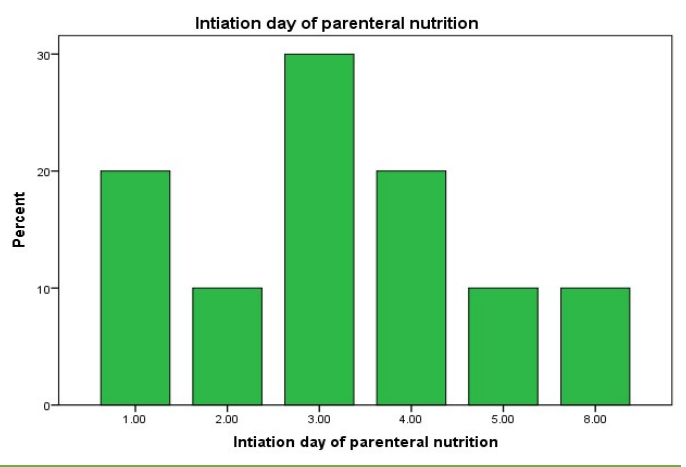

Out of the 10 patients who were given parenteral nutrition during the ITU stay, one was already on total parenteral nutrition due to anastomotic leak which was continued during the stay.

Nine of the patients who were given parenteral nutrition had a documented MUST score of 2 putting them at high risk of malnutrition. We reexamined the tenth patient who didn't have a documented MUST score and found that he had a BMI score of 2. The other two scores were not documented in the notes. So, we concluded that despite the issues of documentation this patient would have still scored a MUST score of 2 . The indications to commence parenteral nutrition was variable. 
Table 8: Indications for commencing parenteral nutrition

\begin{tabular}{|l|l|}
\hline Indications & Frequency \\
\hline $\begin{array}{l}\text { Already on total parenteral nutrition due to } \\
\text { anastomotic leak of bowel surgery }\end{array}$ & 1 \\
\hline Anastomotic leak due to bariatric surgery & 1 \\
\hline $\begin{array}{l}\text { Paralytic ileus / Surgical team requesting to } \\
\text { avoid enteral }\end{array}$ & 6 \\
\hline $\begin{array}{l}\text { Unable to achieve adequate nutrition by } \\
\text { enteral pathway }\end{array}$ & 2 \\
\hline
\end{tabular}

The length of ITU stay ranged from 1 to 15 days during this sample period. The mean duration of ITU stay in this study was 5.34 days.

The patients who received PN had a prolonged ITU stay compared to the ones who received only EN. The mean ITU stay of PN group was 8.7 days vs 4.47 in the non PN group.

Figure 2: Mortality distribution amongst the patients who received parenteral nutrition and those who didn't

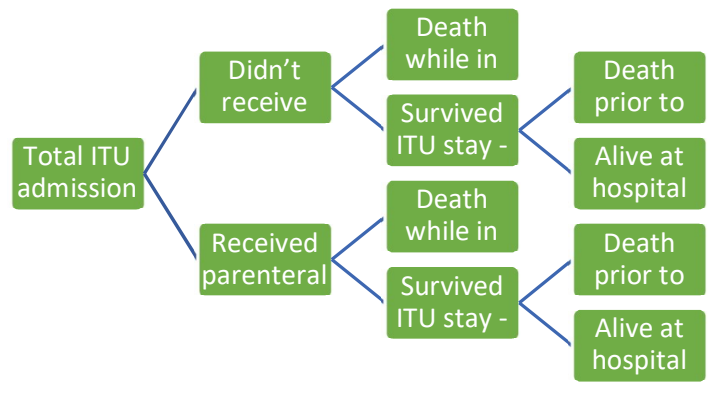

The mortality for all the admissions during ITU stay in this study was $23 \%$. The ITU mortality was higher in the PN group and was $30 \%$. Out of the 77 patients who survived to be discharged from the ITU, 93\% survived to be discharged from the hospital. The overall survival was $72 \%$ among patients who were admitted to the ITU and $50 \%$ among the patients who received PN.

\section{Discussion}

It was apparent to us from the above analysis that PN was not prescribed to adequately nourished patients. This is in keeping with the standards set by the East of England Critical care Network. Out of the sample population only $10 \%$ of the patients received parenteral nutrition and they were all at high risk of malnutrition as assessed by the MUST score. The study confirmed 100\% compliance to the standards set with regards to initiation of PN.

The MUST score documentation reveals that $44 \%$ of our ITU admissions are at high risk of malnutrition. Although the ESPEN guidelines recommends $\mathrm{PN}$ initiation within 24 to 48 hours in patients who are not expected to be on normal nutrition by three days, it does not take into account the risk of malnutrition scoring systems. ${ }^{4}$

Albumin can be used to assess the level of nutrition in general population. ${ }^{7}$ The advantages are that it is a low-cost investigation and routinely done as part of initial biochemical work up. But the disadvantage is that it might not represent the nutrition level alone. Human albumin solutions are part of fluid resuscitation and this might contribute to increased levels. ${ }^{8}$ On the other hand, it may be also decreased due to dilution by crystalloid resuscitation and fluid retention due to kidney injury. Further, it can be lost from the system due to glomerular or intestinal villi damage. Albumin synthesis may also be affected by liver failure.

Although albumin is not the ideal nutrition bio marker, we used it in this study as it is a freely available test and done in all critically ill patients. The normal albumin concentration is generally between 35 to $55 \mathrm{~g} / 1$ and only $14 \%$ of the patients in this study had their albumin concentration equal or above $35 \mathrm{~g} / 1$. The mean concentration was $26.85 \mathrm{~g} / 1$. Looking at both the MUST score and the albumin concentration, we can infer that the patients in this study were malnourished and critically ill.

The mean ITU stay was longer in the parenteral nutrition group (8.7 days) in this study. The ITU and hospital mortality was higher in PN group at $30 \%$ and $50 \%$. We didn't compare any other complications.

\section{Conclusion}

All patients who received PN during the said period were at higher risk of malnutrition which shows $100 \%$ compliance of the standard set by the East of England critical care operational delivery network.

We are planning to restudy the data after taking actions to make sure that the MUST nutrition assessment is completed in $100 \%$ of the patients. 


\section{References}

1. Hejazi N, Mazloom Z, Zand F, Rezaianzadeh A, Amini A. Nutritional Assessment in Critically Ill Patients. Iran J Med Sci. 2016;41(3):171-9.

https://drive.google.com/file/d/0BwwIbI4F418eGpuaFg4Z1RGZ1E/view PMid:27217600

2. Casaer MP, Mesotten D, Hermans G, Wouters PJ, Schetz M, Meyfroidt G et al. Early versus late parenteral nutrition in critically ill adults. N Engl J Med 2011;365:506-17. https://doi.org/10.1056/NEJMoa1102662 PMid:21714640

3. The magnificent seven. Evidence based quality principles agreed by all critical care units in the east of England.

https://drive.google.com/file/d/0BwwIbI4F418eGpuaFg4Z1RGZlE/view

4. Singer P, Berger MM, Van den Berghe G, Biolo G, Calder P, Forbes A et al. ESPEN Guidelines on Parenteral Nutrition: Intensive care. Clin Nutr ESPEN. 2009;28:387-400.

https://doi.org/10.1016/j.clnu.2009.04.024

PMid: 19505748

5. McClave SA, Taylor BE, Martindale RG, Warren MW, Johnson DR, Braunschweig $\mathrm{C}$ et al.
6. Guidelines for the Provision and Assessment of Nutrition Support Therapy in the Adult Critically Ill Patient: Society of Critical Care Medicine (SCCM) and American Society for Parenteral and Enteral Nutrition (A.S.P.E.N.). J Parenter Enteral Nutr. 2016; 40(2):159-211. https://doi.org/10.1177/0148607115621863 PMid:26773077

7. Takır HB, Karakurt Z, Saltürk C, Balcı M, Kargın F, Moçin OY et al. Does Total Parenteral Nutrition Increase the Mortality of Patients with Severe Sepsis in the ICU? Turk Thorac J 2015; 16: 53-8. https://doi.org/10.5152/ttd.2015.4323

PMid:29404078 PMCid:PMC5783060

8. Working group of College of Anaesthesiologists of Sri Lanka. Guidelines on nutritional support in ICU. Published January 2014.

9. Vincent JL, Russell JA, Jacob M, Martin G, Guidet B, Wernerman $\mathrm{J}$ et al. Albumin administration in the acutely ill: what is new and where next? Crit Care. 2014;18:231. https://doi.org/10.1186/cc13991

PMid:25042164 PMCid:PMC4223404 